\title{
The role of ERNi-1 wire on Microstructure and Properties of Pure Nickel N6 Plasma Arc Welding joint
}

\author{
Ting Xing Chai ${ }^{a *}$, Liang Liang Zhang ${ }^{a} \mathbb{1}$, Xi Jing Wang ${ }^{b}$ and Hong Tong $X u^{a}$ \\ ${ }^{a}$ Lanzhou City University, School of Bailie Mechanical Engineering, Lanzhou 730070, China. \\ ${ }^{b}$ Lanzhou University of Technology, State Key Laboratory of Advanced Processing and Recycling of \\ Non-ferrous Metals, Lanzhou 730050, China.
}

Received: May 29, 2020; Revised: November 01, 2020; Accepted: November 11, 2020.

\begin{abstract}
The butt welding tests of $5.5 \mathrm{~mm}$ thick pure nickel $\mathrm{N} 6$ plate were carried out by plasma arc welding (PAW) and ERNi-1wire-filled PAW. And the differences in microstructure and properties between two kinds of joints were studied. The results show that the wire-filled pure nickel N6 joint has good appearance without defects such as pores, cracks, and undercuts. Pure nickel N6 weld is single-phase austenite structure, and no phase transformation occurs during heating or cooling. The weld zone of PAW joint is characterized by coarse columnar grain with average grain size of $125.8 \mu \mathrm{m}$, while the weld zone of wire-filled joint is equiaxed grain with average grain size of $54.8 \mu \mathrm{m}$. The tensile strength of the wire-filled PAW joint is $337 \mathrm{MPa}$ and the elongation after fracture is $44 \%$, which is $11.6 \%$ and $85.5 \%$ higher than that of the PAW joint. The corrosion rate of wire-filled PAW joint is $2.6908 \mathrm{~g} / \mathrm{m}^{2} \mathrm{~h}$, which is lower than that of PAW joint of $2.8820 \mathrm{~g} / \mathrm{m}^{2} \mathrm{~h}$, and the corrosion rates of both joint are higher than the base metal. The alloy elements in the welding wire can supplement the alloy elements burned in the welding process. As the filler metal, the melted wire forms the joint with the melted base metal, avoiding the defects such as undercut and depression. $\mathrm{Al}$ and Ti elements in ERNi-1 wire have deoxidation and nitrogen fixation effect during welding thermal cycle process, which improves the resistance of weld to carbon monoxide and nitrogen porosity. In the process of nitrogen fixation, TiN particles are formed in the crystal or grain boundary. TiN particles at the grain becomes heterogeneous nucleation particles in the grain, which makes a large number of nucleation and increases the nucleation rate. TiN particles at grain boundaries act as "nails" to hinder the migration of austenite grain boundaries. In the deoxidization process, the deoxidized products $\mathrm{Al}_{2} \mathrm{O}_{3}$ and $\mathrm{TiO}_{2}$ are formed. However, large-size inclusions are formed owing to the high content of $\mathrm{Al}$ and $\mathrm{Ti}$ in the molten pool, which affects the performance of the joint. Therefore, the structure and performance of filler wire-filled PAW joint are better than those of PAW joint.
\end{abstract}

Keywords: Pure nickel N6, Plasma arc welding, Corrosion Resistance.

\section{Introduction}

Pure nickel has good strength, plasticity, ductility and magnetic conductivity. It also has good machinability and special electrical, magnetic and thermal expansion properties with high chemical stability under cold and hot conditions ${ }^{1}$. Pure nickel is one of the most corrosion-resistant and good oxidation-resistance metals in heavy non-ferrous metals, especially for caustic soda with the corrosion rate being less than $25 \mu \mathrm{m} /$ year in $50 \%$ boiling caustic soda solution ${ }^{2,3}$. Therefore, pure nickel N6 is one of the most widely used materials in industry, which is widely used in chemical industry, mechanical electronics, food and other fields.

Pure nickel N6 has small solid-liquid temperature range, poor fluidity, sensitivity to dissolve $\mathrm{H}_{2}$ and $\mathrm{O}_{2}$ to form pore in liquid state, and high resistivity and low thermal conductivity. Therefore, it is easy to form defects such as thermal cracks, pore and rapid grain growth caused by welding superheat during welding process, which seriously affects the structure and properties of pure nickel welded joint. Choosing reasonable welding technology is the key to ensure the quality of welded joints. Literature studies show that ${ }^{4-8}$, pure nickel is very easy to appear problems in the welding process.

1. Owing to the low thermal conductivity and the high tendency of welding hot cracks, increasing welding heat input cannot increase penetration depth, but is prone to cracks.

2. Due to small solid-liquid temperature interval, high liquid metal viscosity and poor fluidity, Tungsten Inert Gas welding(TIG) cannot penetrate $5.5 \mathrm{~mm}$ thick plate. Meanwhile, it also has some shortcomings, such as large welding thermal deformation, sensitive welding crystal crack, uneven joint structure, and reduced weld strength and corrosion resistance.

3. When the welding heat input is higher the overheating of the weld metal and the metal near the weld zone results in serious grain coarsening. 
The above problems lead to poor performance of pure nickel welded joints, which seriously restricts the application of pure nickel welded components in engineering practice. Therefore, the key to ensure the quality of welds is to select reasonable welding methods and processes.

For the above reasons, the welding method with low heat input, high penetration and high energy density should be selected in the test. The plasma arc welding (PAW) with high energy is finally selected considering the economy. PAW developed on the basis of TIG with the plasma arc having more concentrated energy density and higher temperature after compression strengthening. Its energy density $\left(5 \times 10^{5} \mathrm{~W} / \mathrm{cm}^{2}\right)$ is much higher than that of argon arc $\left(1 \times 10^{5} \mathrm{~W} / \mathrm{cm}^{2}\right)$. PAW is a welding method widely used in industrial production. At present, PAW can realize the welding of carbon steel ${ }^{9}$, stainless steel $^{10,11}$, aluminum alloys ${ }^{12}$, nickel and its alloys ${ }^{13}$, titanium and its alloys ${ }^{14}$, magnesium and its alloy ${ }^{15}$, copper and its alloys ${ }^{16}$.

In this paper, PAW and PAW with wire-filled were used to welding $5.5 \mathrm{~mm}$ pure nickel N6 plate, respectively. After welding, the welded joints obtained by the optimum process parameters under the two methods were compared and studied from the aspects of microstructure and mechanical properties in order to clarify the reasons for the difference between the welded joints and further improve the performance of the pure nickel N6 joints. This study provides experimental analysis and data reference for the application of two kinds of pure nickel N6 welded joints in corrosive environment.

\section{Materials and Methods}

\subsection{Material}

The material is hot-rolled pure nickel N6 plate with size of $100 \mathrm{~mm} \times 50 \mathrm{~mm} \times 5.5 \mathrm{~mm}$. ERNi-1 wire with diameter of $1.0 \mathrm{~mm}$ was used in plasma arc filler welding process. The chemical compositions of N6 and ERNi-1 wire are shown in Table 1, and the physical and mechanical properties of N6 are shown in Table 2. During welding process, the $99.99 \%$ pure argon was used as protective gas and plasma gas.

\subsection{Welding procedure}

This paper uses a set of automatic plasma arc welding equipment with Omron CP1H PLC as the control core. The equipment includes power source, welding torch, welding trolley, air circuit, cooling water circulation system, automatic wire feeding system and control system. PAW and PAW with wire-filled were respectively used to welding $5.5 \mathrm{~mm}$ pure nickel N6 sheet, as shown in Figure 1. Before welding, the $2000 \#$ sandpapers were used to grind the $50 \mathrm{~mm}$ area near the welding area of plate in order to remove oxide film on the plate surface. Then, the acetone was used to clean and remove oil stain on the surface to ensure that the surface of the test plate is clean and pollution-free. The welded joint is in the form of butt joint, with "I" shaped groove. A gap of $0.7 \mathrm{~mm}-1 \mathrm{~mm}$ is reserved in the center to ensure the penetration, as shown in Figure 2. In order to obtain the welded joint of single welding double forming, the position of

Table 1. The chemical composition of the N6the and ERNi-1(Wt, \%)

\begin{tabular}{lcccccc}
\hline \multicolumn{1}{c}{ Elements } & $\mathrm{C}$ & $\mathrm{Mn}$ & $\mathrm{Fe}$ & $\mathrm{P}$ & $\mathrm{S}$ & $\mathrm{Si}$ \\
\hline N6 & 0.081 & - & 0.062 & - & 0.015 & 0.073 \\
\hline ERNi-1 & 0.15 & 1.0 & 1.0 & 0.03 & 0.015 & 0.75 \\
\hline \multicolumn{1}{c}{ Elements } & $\mathrm{Cu}$ & $\mathrm{Ni}$ & $\mathrm{Al}$ & $\mathrm{Ti}$ & $\mathrm{Others}$ & \\
\hline N6 & - & $99.7-99.8$ & $\mathrm{Bal}$ & 0.056 & - & \\
\hline ERNi-1 & 0.25 & 93.0 & 1.5 & $2.0-3.5$ & $\leq 0.5$ & \\
\hline
\end{tabular}

Table 2. The physical properties and mechanical properties of the N6

\begin{tabular}{ccccc}
\hline Density g/cm $/ \mathrm{cm}^{3}$ & Melting point $\mathrm{T} /{ }^{\circ} \mathrm{C}$ & Boiling point $/{ }^{\circ} \mathrm{C}$ & $\begin{array}{c}\text { Thermal conductivity } \\
\lambda / \mathrm{W} \cdot \mathrm{m}^{-1} \cdot \mathrm{K}^{-1}\end{array}$ & $\begin{array}{c}\text { Specific heat } \\
\mathrm{c} / \mathrm{KJ} \cdot \mathrm{kg}^{-1} \cdot \mathrm{K}^{-1}\end{array}$ \\
\hline 8.89 & 1453 & 2915 & 92 & 0.64 \\
\hline $\begin{array}{c}\text { Linear expansion } \\
\text { coefficient } \alpha / 10^{-6} \cdot \mathrm{K}^{-1}\end{array}$ & Tensile strength $\mathrm{R}_{\mathrm{m}} / \mathrm{Mpa}$ & Yield strength $\mathrm{R}_{\mathrm{p} 0.2} / \mathrm{Mpa}$ & Elongation A $/ \%$ & \\
\hline 13.3 & $300 \sim 400$ & $\geq 150$ & $\geq 35$ & \\
\hline
\end{tabular}

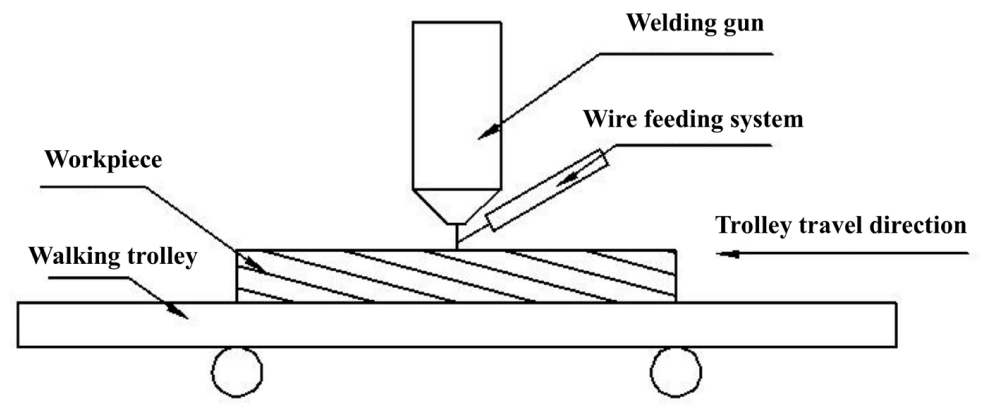

Figure 1. Schematic diagram of welding process. 
the torch remains unchanged, and the worktable holding the workpiece moves horizontally during the welding process.

According to the weldability of pure nickel, the keyhole PAW method is selected. The main parameters are: welding current $I$ (A), welding speed $V(\mathrm{~mm} / \mathrm{min})$, ion plasmagas flow of $99.99 \%$ pure argon $q(\mathrm{~L} / \mathrm{min})$, protective gas flow of $99.99 \%$ pure $\operatorname{argon} q_{1}(\mathrm{~L} / \mathrm{min})$, distance from nozzle to workpiece $d(\mathrm{~mm})$, nozzle geometry, tungsten pole material and size. In addition, PAW with wire-filled matches an automatic wire feeding system based on PAW equipment. During welding process, the $1 \mathrm{~mm}$ ERNi-1 welding wire was fed into the molten pool by automatic wire feeding equipment. So,during PAW with wire-filled process, the wire feeding speed $V_{l}(\mathrm{~cm} / \mathrm{min})$, wire feeding angle $\left(^{\circ}\right)$ and wire feeding method should be considered. The effect of main process parameters on the microstructure and properties of joints was studied through a large number of tests in the early stage, and the optimum process parameters were obtained, as shown in Table 3, 4 .

\subsection{Analysis methodology}

After lots of welding process tests, the optimal welding process specifications of the two welding methods, suitable for the $5.5 \mathrm{~mm}$ N6 plate were determined and used to obtain the joints. After welding, the welded joints were processed into standard tensile specimens according to GB/T2651-2008. Tensile tests were carried out using AG-10TA universal material testing machine to test the tensile strength $\mathrm{Rm}$ and fracture elongation A. Tensile was conducted three times for each group of parameters, and the mean values of three times were taken as test results. According to the requirements of GB/T 2654-2008, the microhardness of two welded joints in different areas was tested by HV-1000 tester, and the hardness curve distribution was drawn.

The metallographic samples were cut perpendicular to the direction of the weld. After polished, the samples were etched by $10 \mathrm{ml}$ distilled water, $50 \mathrm{ml}$ nitric acid and $50 \mathrm{ml}$ glacial acetic acid mixed solution for 3-5s. The microstructures of joints were observed by MeF3 metallographic microscope and QUANTAFEG-450 scanning electron microscope with energy dispersive spectrometer was used to analyze the chemical composition of precipitates in welds. The corrosion rate of two kinds of joints in $6 \% \mathrm{FeCl}_{3}$ solution was measured by room temperature immersion corrosion method. The corrosion morphology was observed and the corrosion mechanism of the two samples in the corrosion solution was analyzed.

\section{Results and discussions}

\subsection{Macro-morphology of joints}

According to the optimal process parameters in Table 4, the welded joints with good appearance were selected as the research object, as shown in Figure 3. As can be seen from Figure 3, the joint of PAW is poorly formed. There are defects in the joint, such as undercut, indicated by the red arrow in Figure 3 and porosity, indicated by the white arrow in Figure 3. The shape of wire-filled PAW joint is more beautiful with the surface being continuous, smooth and even with fish scale ripple. And there are no defects such as undercut, porosity and depression. The improvement of the appearance of wire-filled PAW joint is closely related to the filling of ERNi-1 wire in the welding process, which will be elaborated in the following part of the paper.

\subsection{Microstructure of base metal and joint}

The microstructure of base metal was shown in Figure 4. For pure nickel N6, there is austenite equiaxed grain structure, and the average grain size is $10.2 \mu \mathrm{m}$. Owing to the N6 plate having been hot rolled, there is annealing twin structures in the grains, as indicated by the red arrow in Figure 4.

The pure nickel N6 is single phase austenite with no phase transformation appearance during heating and cooling under any conditions. Therefore, the structure of weld metal and near weld zone is still single-phase austenite, and only coarse austenite grains exist in superheated zone. During the cooling process of molten pool, pure nickel does not undergo

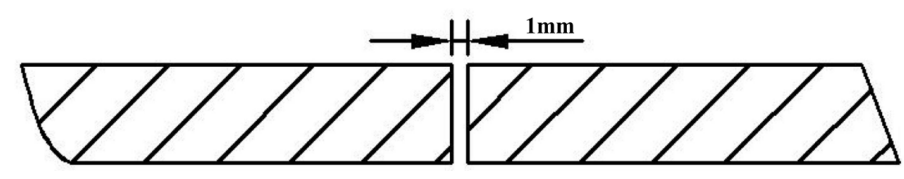

Figure 2. Schematic diagram of butt joints.

Table 3. Optimum welding parameters of two welding methods for $5.5 \mathrm{~mm}$ N6 plate

\begin{tabular}{|c|c|c|c|c|}
\hline \multirow{2}{*}{ Methods } & Welding current & Plasma gas flow & Welding speed & Protective gas flow \\
\hline & $\mathrm{A}$ & $\mathrm{L} / \mathrm{min}$ & $\mathrm{mm} / \mathrm{min}$ & $\mathrm{L} / \mathrm{min}$ \\
\hline PAW & 170 & 1.5 & 170 & $13 \sim 15$ \\
\hline PAW with wire & $175 \sim 180$ & 1.5 & $170 \sim 175$ & $13 \sim 15$ \\
\hline
\end{tabular}

Table 4. Optimum welding parameters of two welding methods for $5.5 \mathrm{~mm}$ N6 plate-continued

\begin{tabular}{|c|c|c|c|}
\hline Back protective flow & Wire feeding speed & \multirow{2}{*}{ Wire feeding angle ${ }^{\circ}$} & \multirow{2}{*}{ Wire feeding method } \\
\hline $\mathrm{L} / \mathrm{min}$ & $\mathrm{cm} / \mathrm{min}$ & & \\
\hline $8 \sim 10$ & - & - & - \\
\hline $8 \sim 10$ & $60 \sim 65$ & 65 & Pre-feeding wire \\
\hline
\end{tabular}



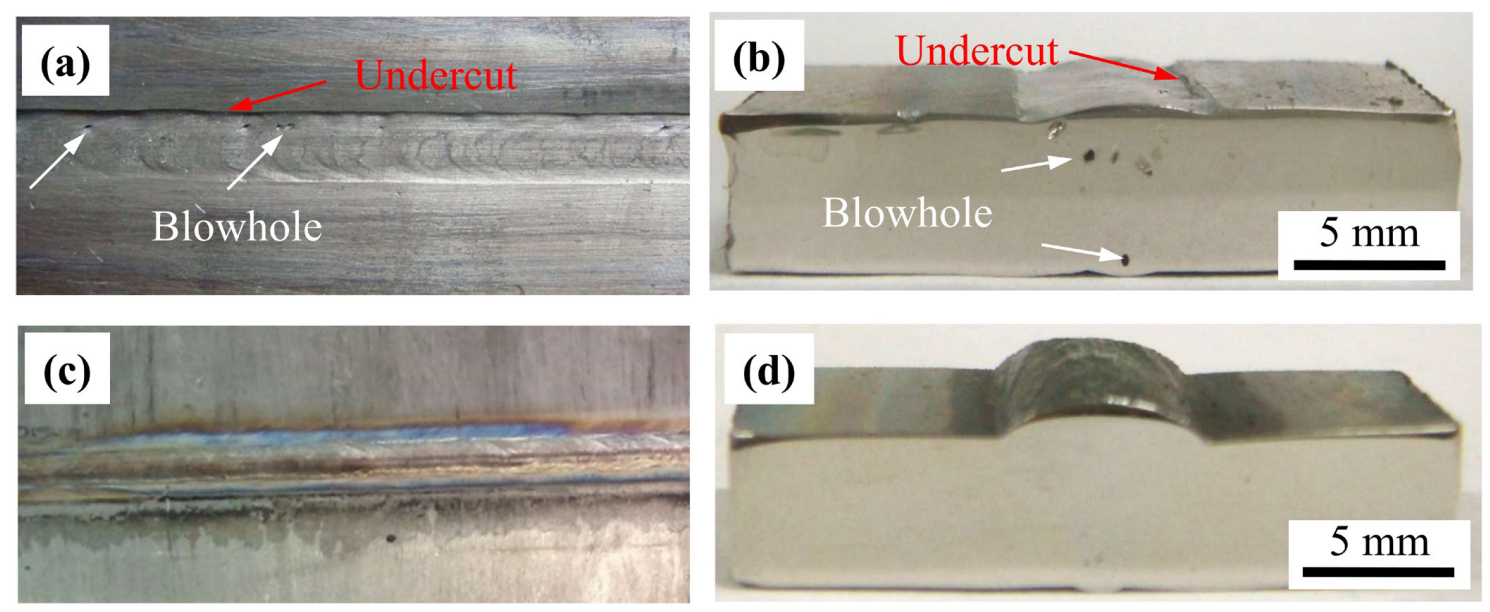

Figure 3. The macro-morphology of two kinds of joints(a)Upper surface of PAW joint(b)Cross-section of PAW joint (c)Upper surface of wire-filled PAW joint (d)Cross-section of wire-filled PAW joint

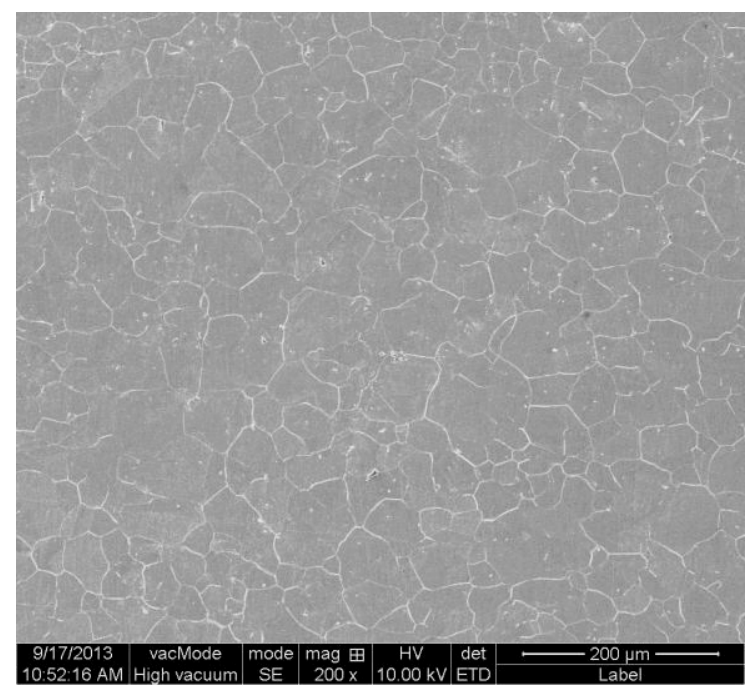

Figure 4. Microstructure of base metal.

phase change and austenite grains grown in the heating process do not have recrystallization refining effect by phase transformation during cooling process. Therefore, coarse austenite grains only exist in the superheated zone of joints.

Figure 5 shows the microstructures in different regions of PAW joints. It can be seen from Figure 5a that the grains in the welded joint near the base metal are finer, and the side closer to the heat affected zone (HAZ) appears larger equiaxed grains, which is due to intense overheating. At the same time, there is associated crystallization in HAZ. As the metal crystallization in the molten pool generally starts from the boundary of the molten pool, the non-spontaneous nuclei adhere to the surface of pure nickel metal grains in semi-melting state, and grow toward the center of the weld as columnar crystals, forming associated crystals. As shown in Figure 5b, the grain in HAZ grows due to overheating, with an average grain size of $72.4 \mu \mathrm{m}$.

The grain size in this region is smaller than that in the weld zone, and the grain size is uneven. The grain size near the weld zone is coarser than that near the base metal. The grain size in HAZ of PAW joint, having uniform grain size and wider the heat affected zone is wide, is coarser than that of wire-filled PAW joint.

Figure $5 \mathrm{c}$ shows that the grains in the weld zone are coarse columnar crystals with obvious orientation and the average grain size is $125.8 \mu \mathrm{m}$. This is related to the characteristics of pure nickel. Owing to high thermal conductivity, small temperature interval between solid and liquid phases, high viscosity of liquid metal and poor fluidity sufficient heat input must be ensured in order to penetrate $5.5 \mathrm{~mm}$ thick sheet at one time. So, overheating of molten pool results in severe coarsening of weld grain.

During the welding thermal cycle, the liquid metal is easy to overheat, which results in a large number of alloy elements burning in the molten pool ${ }^{17}$. The number of nonspontaneous nucleating particles in the molten pool decreases greatly, which leads to columnar crystals in the welded joint. At the same time, owing to the high central temperature of the molten pool and the cooling rate, equiaxed crystals are not easy to appear and columnar crystals are easy to appear.

Figure 6 shows the microstructures in different regions of wire-filled joint. Figure $6 \mathrm{~b}$ is the microstructure of HAZ in wire-filled PAW joint, which results in grain growth due to overheating. The average grain of HAZ of wire-filled PAW joint is $37.8 \mu \mathrm{m}$. However, the grain size of HAZ in both joints is smaller than that in weld zone. This is due to recrystallization and nucleation of HAZ grains into coarse equiaxed grains driven by energy storage during welding thermal cycle. At the same time, some grains recrystallize when the temperature of heat affected zone is too high and large grains migrate through grain boundaries and annex small grains around them to form larger grains, but the grains in this area are not over-grown. The grain size of HAZ in wire-filled PAW joints is slightly higher than that in PAW joint. It may be that filled wire effectively reduces the superheat of molten pool, resulting in a certain degree of restraint of grain growth in HAZ in wire-filled PAW joint.

The weld zone of wire-filled PAW joint shown in Figure 6c is austenite equiaxed grain structure. The average grain size 

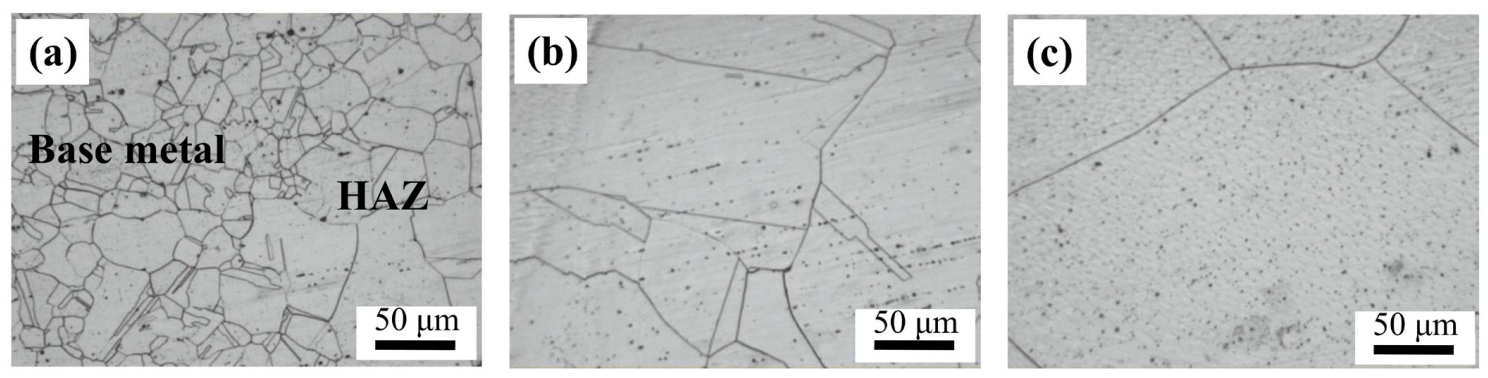

Figure 5. Microstructure in different regions of PAW joint (a)welded joint (b) heat affected zone(c)weld zone.
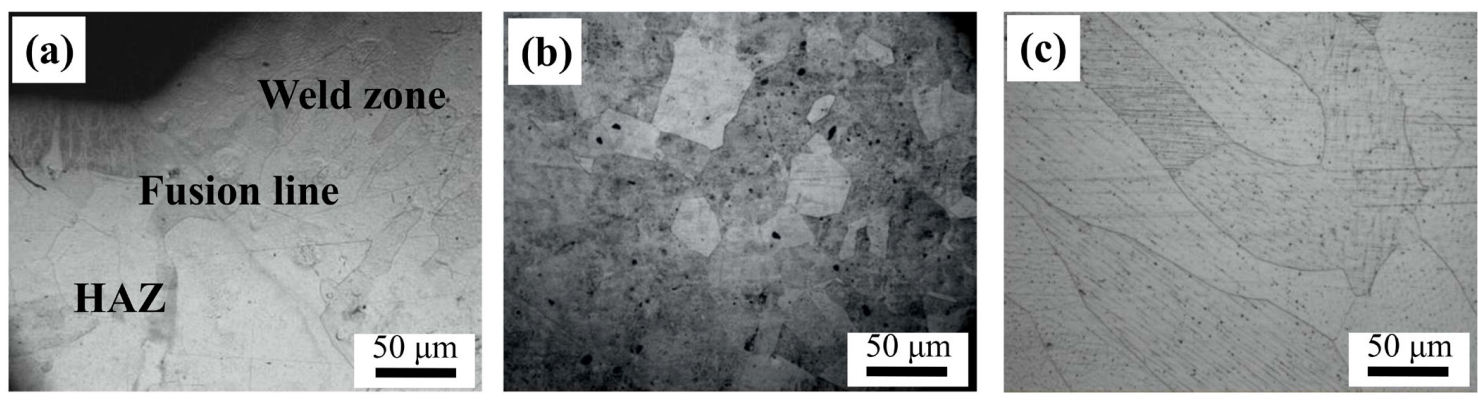

Figure 6. Microstructure in different regions of wire-filled PAW joint(a)welded joint (b)heat affected zone (c)weld zone.

is $54.8 \mu \mathrm{m}$. Compared with the grain size of $125.8 \mu \mathrm{m}$ in PAW joint, the grain size of wire-filled PAW joint is much smaller.

The reasons are as follows. Firstly, the ERNi-1 wire makes up for the alloy elements, which are easy to be burnt out during the welding process, resulting in the increase of the constitutional supercooling in the molten pool, and further promotes the heterogeneous nucleation of the crystal in the molten pool. During the wire-filled welding process, Ti element (2.0\%-3.5\%)in the ERNi-1 wire transits to the molten pool, providing a large number of refractory particles for heterogeneous nucleation of crystals in the molten pool, and increases the nucleation rate and refines the crystalline grains. According to the literature $^{18}$, molten pool crystallization is a process of nucleation formation and growth. Heterogeneous nucleation is the main mechanism of solidification of liquid metal in the weld pool, because the liquid metal in the weld pool is superheated and the possibility of spontaneous nucleation is small.

Second, TiN with high melting point is formed in the wire-filled welding, which acts as a "nail" to hinder the migration of austenite grain boundary. The welding heat input $(18 \mathrm{~kJ} / \mathrm{cm})$ of PAW is close to that of wire-filled PAW $(18.5 \mathrm{~kJ} / \mathrm{cm})$. However, during wire-filled PAW process, the melting wire consume a certain amount of energy with the volume of molten pool be slightly reduced, which reduces the cooling time of liquid molten pool and accelerates the cooling rate slightly, and play a positive role in grain refinement of weld zone to a certain extent. The comprehensive effect of the above factors result in grain size of wire-filled PAW joint is smaller than that of PAW joint. The grain sizes of base metal and different regions of welded joints are shown in Figure 7.

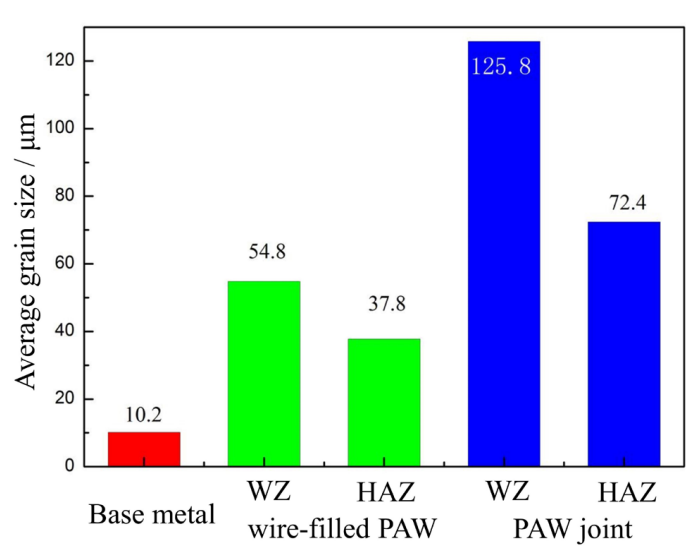

Figure 7. Grain Size in different zones of joints.

\subsection{Mechanical properties analysis}

\subsubsection{Tensile and impact test}

Tensile tests were carried out on base metal, PAW joints and wire-filled PAW joints using universal material testing machine to test the tensile strength $\mathrm{Rm}$ and fracture elongation $A$. The impact energy of different specimens was tested by Charpy V notch impact test method. The test results are shown in Table 5.

The tensile test results of welded joints show that the average tensile strength and elongation of base metal with $5.5 \mathrm{~mm}$ thickness are $366 \mathrm{MPa}$ and $60 \%$, respectively. The maximum tensile strength of the PAW joint is $302 \mathrm{Mpa}$, which reaches $82.5 \%$ of the strength of base metal and the fracture 
location is in the weld center with the fracture elongation $23.7 \%$. The average tensile strength of wire-filled PAW joint is $337 \mathrm{MPa}$, which reaches $92.07 \%$ of the base metal strength, and the fracture location is in the HAZ with the average fracture elongation $44 \%$. The tensile strength and fracture elongation of wire-filled PAW joint increased by $11.6 \%$ and $85.5 \%$ respectively compared with that of PAW joint. The impact test results show that the impact toughness of base metal is better than that of two kinds of joints. And impact toughness of wire-filled PAW joint is better than that of PAW joint. The impact energy of base metal, wire-filled PAW joint and PAW joint are 216.4J, 186.2J and 141.4J.
The impact energy of wire-filled PAW joint is $31.7 \%$ higher than that of PAW joint

Figure 8 shows the tensile fracture morphology of base metal and welded joints. Figure 8a shows the tensile fracture morphology of the base metal. The fracture surface of the base metal shows ductile fracture with many dimples. Figure 8 (b) shows the tensile fracture morphology of the PAW joint. The fracture surface shows brittle fracture with river pattern morphology. Figure $8 \mathrm{c}$ is the tensile fracture morphology of wire-filled joint. The fracture shows a mixed fracture of toughness and brittleness with large and shallow dimples in local zone ${ }^{19,20}$. The number of precipitates in

Table 5. Mechanical properties and fracture location of base metal and welded joints

\begin{tabular}{|c|c|c|c|c|c|}
\hline & $\begin{array}{c}\text { Tensile strength } \\
\mathrm{Rm} / \mathrm{Mpa}\end{array}$ & $\begin{array}{c}\text { Fracture } \\
\text { elongation } \mathrm{A} / \%\end{array}$ & Fracture location & Fracture samples & $\begin{array}{l}\text { Impact } \\
\text { energy }\end{array}$ \\
\hline Base metal & 366 & 60 & & & $\mathrm{Ak} / \mathrm{J}$ \\
\hline PAW joint & 302 & 23.7 & weld center & & 216.4 \\
\hline $\begin{array}{l}\text { Wire-filled } \\
\text { PAW joint }\end{array}$ & 337 & 44 & HAZ & & 141.4 \\
\hline
\end{tabular}
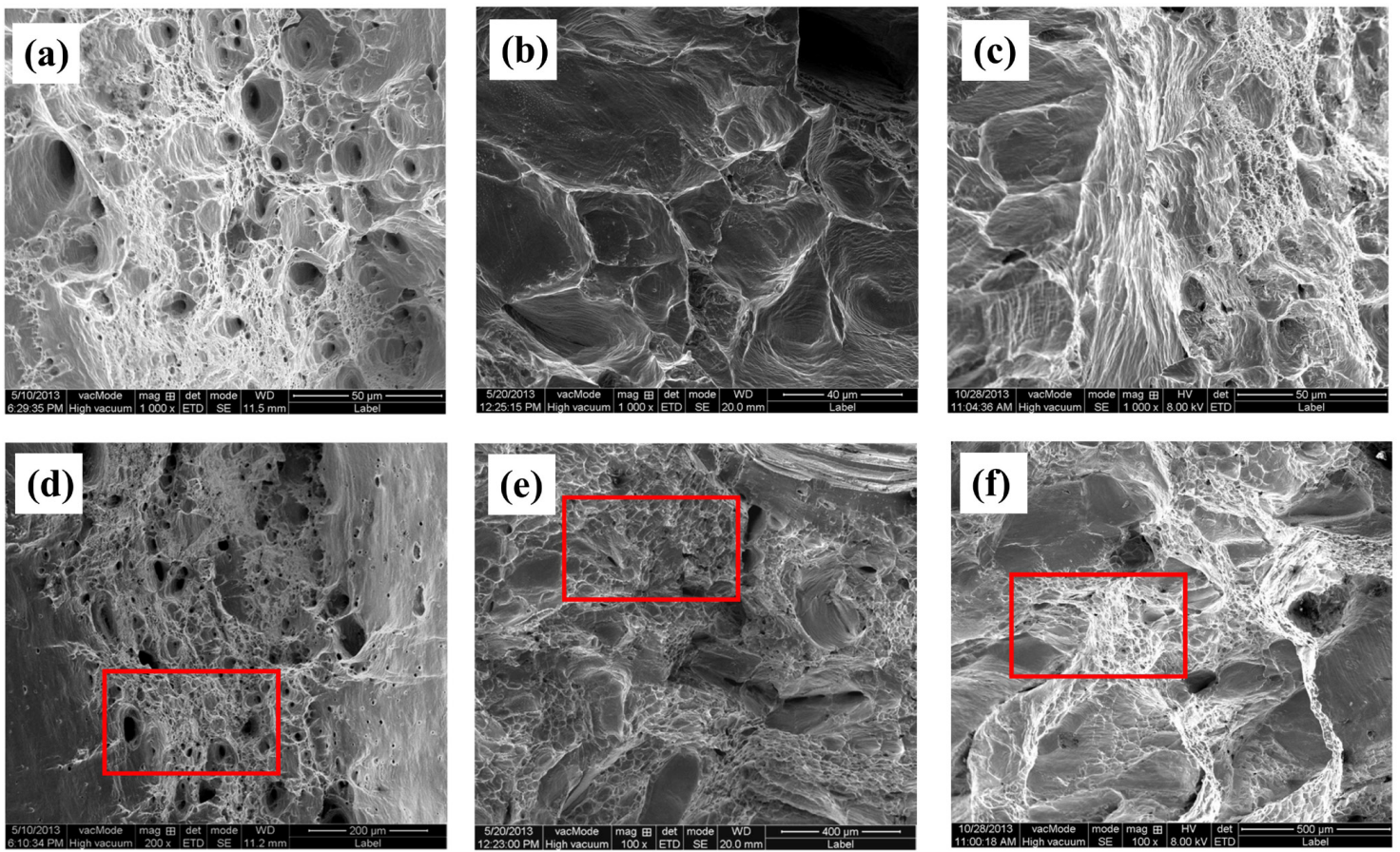

Figure 8. Tensile fracture of base metal and welded joints(a)base metal(b)PAW joint(c)wire-filled PAW joint (a), (b), (c) high-magnification photograph, (d), (e) e (f) SEM photograph of macro fracture 
fracture of pure nickel is small and its size is less than $2 \mu \mathrm{m}$ with sparse distribution.

\subsubsection{Microhardness}

The microhardness of the welded joint was measured with moving from weld center to base metal. The load was $25 \mathrm{Kgf}$ with 15 s loading time. The microhardness distribution curves of different regions of the welded joint were drawn in Figure 9.

The following information can be obtained from Figure 9 . Fristly, the change trend of microhardness in base metal of two kinds of welded joints is same owing to pure nickel N6 being hot rolled structure with fine and uniform grains and high microhardness. Secondly, the minimum microhardness of both joints occurs in HAZ, which is due to the austenite grain growth and the decrease of hardness with the heating of HAZ during welding. The microhardness of HAZ of wire-filled PAW joint is higher than that of PAW joint. The Hall-Petch formula ${ }^{21}$, based on the dislocation stacking theory of single crystal and polycrystalline materials, is the relationship between material microhardness and grain size, which can be rewritten as $\mathrm{H}_{\mathrm{v}}=\mathrm{H}_{\mathrm{o}}+\mathrm{kd}^{-1 / 2}$, which is one of the guiding laws for improving the strength of metal materials for a long time. The $\mathrm{K}$ value in microhardness, the slope of the function curve of yield stress with $\mathrm{d}^{-1 / 2}$, is related to the defects contained in the material, the surface finish of the material, and the density of the material ${ }^{22}$.According to the

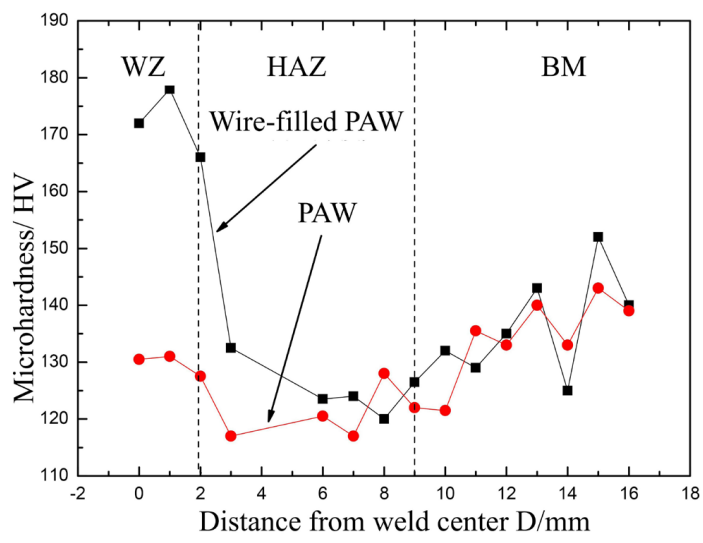

Figure 9. Microhardness distribution curve of welded joints
Hall-Petch formula, the reason why the microhardness of the HAZ of wire-filled joint is higher than that of the PAW joint can be explained.

Finally, for the weld zone of the two kinds of joints, the grain size of PAW joint is coarse with low hardness. In the process of wire-filled PAW joint, the transition of Ti in the wire into the molten pool can refine the grain and play the role of fine grain strengthening. At the same time, the precipitation of $\gamma^{\prime}$ phase and TiN, TiC in the wire-filled PAW joint will produce strengthening effect, which together lead to the increase of the hardness. Literature studies show that the larger the grain size of the weld, the lower the hardness and the more precipitated phases in the weld, the higher the hardness of the weld ${ }^{23-25}$.

\subsubsection{Corrosion resistance analysis}

Soaking corrosion tests of base metal and joint samples were carried out. The prepared specimens were weighed and put into $300 \mathrm{~mL} 6 \% \mathrm{FeCl}_{3}$ solution for static corrosion weightlessness test at room temperature. Then, the samples were put on the plastic wire and immersed parallel in the corrosive solution. The immersion depth and the distance between the samples corrosive solution should be kept more than $2 \mathrm{~cm}$ with $75 \mathrm{~h}$ corrosive time. The corrosion morphology and corrosion rates of different samples are shown in Figure 10 and Figure 11, respectively.

It can be seen from Figure 10 that the surface of base metal is uniformly corroded without deep corrosion pits; the corrosion of wire-filled PAW joint and PAW joint is more serious than that of base metal, especially there are many and deeper corrosion holes on the surface of PAW joint, which has typical corrosion characteristics.

It can be seen from Figure 11 that the corrosion status of different samples in $6 \% \mathrm{FeCl}_{3}$ solution are serious. This is because the passivation film or oxide film on pure nickel surface may have pitting corrosion in the corrosive medium containing chloride ions and chlorides. Especially when there are mechanical cracks, scratches and inclusions on the passivation film surface, the defects cause the nonuniform thickness of passivation film and easy to induce local damage. These phenomena are related to the following two aspects. On the one hand, $\mathrm{FeCl}_{3}$ belongs to acidic salts, which produce acid in the hydrolysis process. It has both oxygen depolarization corrosion and hydrogen depolarization corrosion on pure nickel. And the corrosion rate is close to
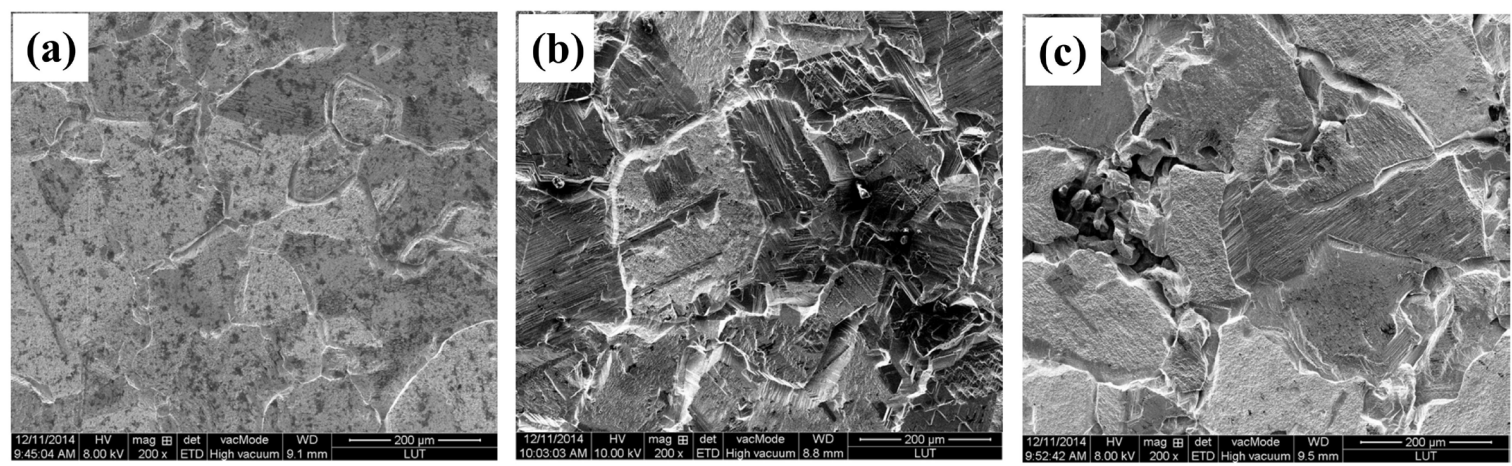

Figure 10. SEM morphology of samples corroded in $6 \% \mathrm{FeCl}_{3}$ solution (a) base metal (b) wire-filled PAW joint (c) PAW joint 
that of acid solution with the same $\mathrm{PH}$, which promotes corrosion for pure nickel to a certain extent. On the other hand, when pure nickel is in passive state, the corrosion reaction still occurs with dynamic equilibrium. However, the activation of $\mathrm{Cl}^{-}$destroy the dynamic equilibrium state, which will change the dissolution process of pure nickel into an advantage and accelerate the corrosion of pure nickel

From the corrosion morphology and corrosion rate of samples, the corrosion resistance of pure nickel base metal in $6 \% \mathrm{FeCl}_{3}$ solution is the best, followed by wire-filled PAW joint, and PAW joint is the worst. In the process of

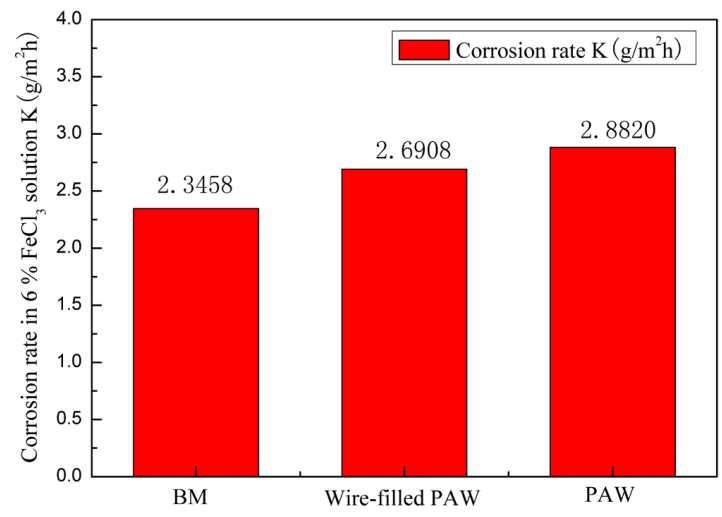

Figure 11. Corrosion rate curves of different samples. fusion welding process, pure nickel is heated and melted locally under the action of welding heat source and during the crystallization process of liquid metal in molten pool, the defects of gas holes, cracks, inclusion and element segregation are easy to occur, which results in the worse uniformity and purity of weld structure than that of base metal. Therefore, although the hardness of wire-filled PAW joint (170HV) is higher than that of base metal (145 HV), the corrosion resistance of wire-filled PAW joint weld becomes worse.

There are $\mathrm{Al}_{2} \mathrm{O}_{3}$ inclusion on the surface of joint, and the interface between $\mathrm{Al}_{2} \mathrm{O}_{3}$ and matrix is corroded seriously, which indicates that the interface between non-metallic inclusions and matrix is the worst corrosion resistance area. There is an inhomogeneity of chemical composition between non-metallic inclusions and metal matrix, and corrosive micro-couples can be formed between non-metallic inclusions and metal matrix in corrosive medium. If the electrochemical activity of the inclusion is higher than that of the metal matrix, the inclusion will be dissolved preferentially as an anode. Conversely, the metal matrix dissolves preferentially ${ }^{26,27}$. Aluminum-rich inclusions are more stable than pure nickel matrix. Corrosion micro-couples composed of pure nickel and $\mathrm{Al}_{2} \mathrm{O}_{3}$, pure nickel matrix dissolves preferentially forming "micro-gap" between the inclusions and the surrounding matrix, which further dissolves into a "corrosion ditch", as shown in Figure 12. During pitting process induced by $\mathrm{Al}_{2} \mathrm{O}_{3}$
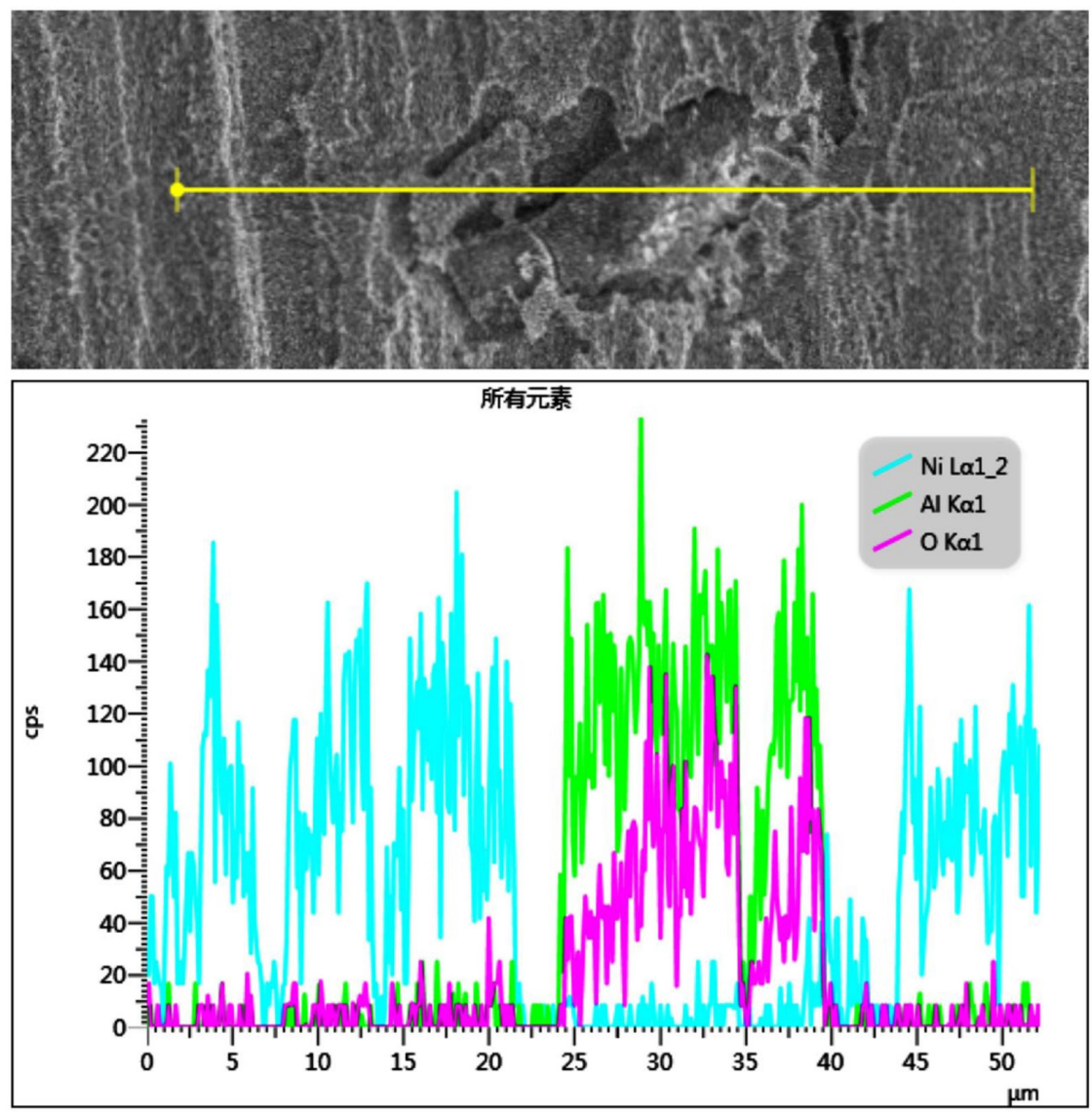

Figure 12. Energy spectrum analysis of inclusions in joint 
inclusions, corrosion dissolution occurs first at the interface between inclusions and metal matrix ${ }^{28}$.

\subsection{Effect analysis of ERNi-1 wire}

The microstructure and properties of PAW joint and wire-filled PAW joint are compared. The results show that the appearance, microstructure and properties of wire-filled PAW joint are better than those of PAW joint. This is due to the role of ERNi-1 wire in the process of welding process.

\subsubsection{Grain refinement}

The grain size of wire-filled PAW joint is finer than that of PAW joint and the mechanical properties are obviously improved, which is related to the Ti content of ERNi-1 wire playing a role in refining weld grain. The precipitated phases in wire-filled PAW joint, analyzed by SEM and EDS, can refine the grain size. There are two common characteristics of the precipitates which can refine the grain in the joint. One, the melting point of precipitated phase must be higher than the temperature of molten pool to ensure the stable state. The other, precipitated phase must have a good lattice matching relationship with pure nickel.

It can be seen from Figure 13 and Table 6 that the size of $\mathrm{TiN}$ and $\mathrm{TiC}$ particles precipitated from wire-filled wire joint is less than $2 \mu \mathrm{m}$. Firstly, the melting points of $\mathrm{TiN}$ and $\mathrm{TiC}$ particles are high, reaching $2950^{\circ} \mathrm{C}$ and $3140^{\circ} \mathrm{C}$, respectively. TiN and $\mathrm{TiC}$ particles can be used as effective nucleation cores and exist stably in the molten pool.

Ti has a strong chemical affinity with nitrogen, oxygen and carbon. TiN and $\mathrm{TiC}$ are continuously precipitated in the process of crystallization. Carbon and nitrogen atoms can be replaced each other, and $\mathrm{TiN}$ and $\mathrm{TiC}$ are separated out alternately in the molten pool. Secondly, according to the lattice matching theory, the heterogeneous nucleation ability of impurity particles in liquid metal is related to the interface energy between crystal nucleus and impurity particles ${ }^{29,30}$.In the heterogeneous nucleation process, the higher the structural similarity (low mismatch degree) between the nucleation and impurity particles, the smaller the interface energy between them, and the higher the nucleation rate to further refine the grains. When the one-dimensional mismatch degree $(\delta) \leq 25 \%$, there is a moderate degree of mismatch between the substrate and the crystal nucleus, the nucleation energy is small, resulting in the increased nucleation rate and refine grain in the weld zone ${ }^{31}$. The one-dimensional mismatch degree ( $\delta$ ) between $\mathrm{TiN}, \mathrm{TiC}$ and pure nickel is $20.3 \%$ and $22.8 \%$, respectively, which indicates that $\mathrm{TiN}$ and $\mathrm{TiC}$ can refine the grain size in the molten pool ${ }^{32,33}$.

As shown in Figure $13 \mathrm{a}$ and $\mathrm{b}$, the precipitated TiN and $\mathrm{TiC}$ are located in the grain and become heterogeneous nucleation particles, which makes a large number of nucleation in the molten pool crystallization process and increases the nucleation rate. As shown in Figure 13c, the precipitated TiN is distributed at the grain boundary and acts as a "nail" to hinder austenite grain growth, thus refining the weld grain ${ }^{34,35}$. There are a lot of fine TiN particles in Ti micro-alloyed steel. After $1350^{\circ} \mathrm{C}$ welding thermal cycle, TiN still exists stably, which can effectively prevent austenite grain growth. The smaller for the size of $\mathrm{TiN}$ and the more for the number of TiN in the weld, the refinement effect is obvious ${ }^{36}$.

\subsubsection{Elimination of pores}

In the welding process of pure nickel N6, owing to the improper welding process or the poor protection effect, the weld is susceptible to pores. The formation process of pores is composed of nucleation and growth. When the pore grows to a certain extent, it begins to float. When the crystallization speed is greater than the pore floating speed, the pores can't escape and remain in the weld. The internal porosity of pure nickel weld is related to oxygen and nitrogen. Oxygen enters into the molten pool to produce $\mathrm{CO}$ through metallurgical reaction, and finally $\mathrm{CO}$ appears in the weld ${ }^{37,38}$. Nitrogen enters the molten pool and causes nitrogen pores. The porosity reduces the effective cross-sectional area and the weld strength and toughness of joint. And the stress concentration appearing around the pores is unfavorable to the dynamic load strength and fatigue strength of welded

Table 6. Chemical constituents of precipitated phases(at. \%).

\begin{tabular}{|c|c|c|c|c|c|c|}
\hline Elements & $\mathrm{C}$ & $\mathrm{N}$ & $\mathrm{O}$ & $\mathrm{Ti}$ & $\mathrm{Ni}$ & Precipitates \\
\hline $\mathrm{a}$ & 7.18 & 47.96 & 5.83 & 38.5 & 0.53 & TiN \\
\hline $\mathrm{b}$ & 7.09 & 0.0 & 1.04 & 3.44 & 88.43 & $\mathrm{TiC}$ \\
\hline $\mathrm{c}$ & 19.19 & 36.82 & 8.92 & 34.66 & 0.41 & TiN \\
\hline
\end{tabular}

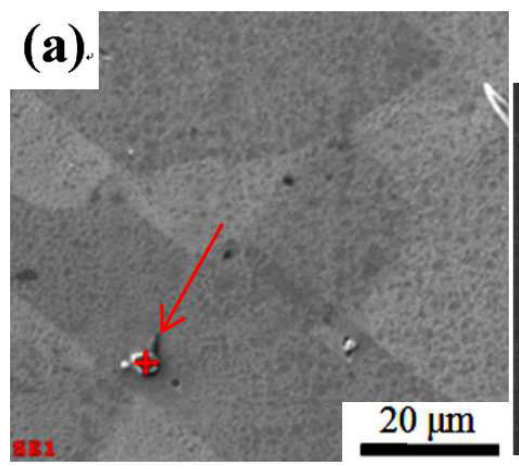

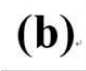

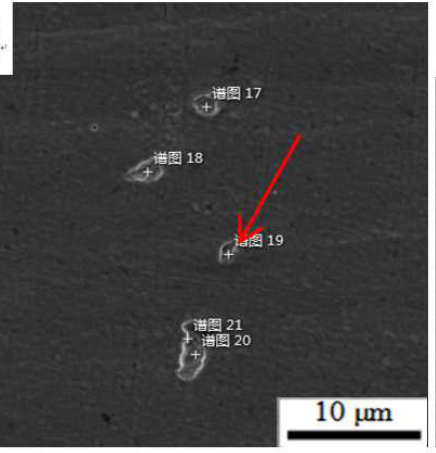

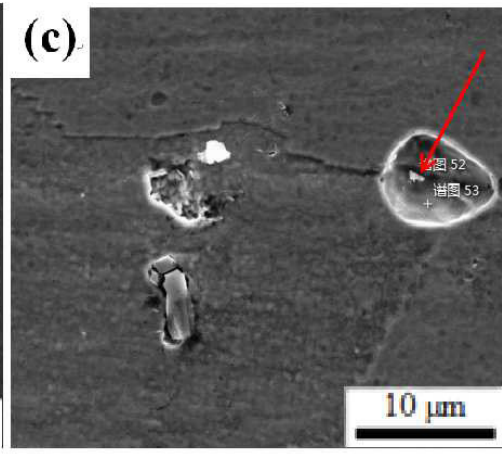

Figure 13. The precipitated phases in wire-filled PAWjoint (a) TiN (b) TiC (c) TiN. 
components. As shown in Figure $4 \mathrm{~b}$ and $d$, the number of pores in the wire-filled PAW joint decreases or disappears.

The reduction of porosity in wire-filled PAW joint is related to $\mathrm{Al}(1.5 \%)$ and $\mathrm{Ti}(2.0 \sim 3.5 \%)$ elements in $\mathrm{ERNi}-1$ wire. $\mathrm{Al}$ and Ti elements are strong oxide forming elements. During the welding thermal cycle process, the tiny deoxidization particles mainly composed of $\mathrm{Al}_{2} \mathrm{O}_{3}$ and $\mathrm{TiO}_{2}$, dispersing in the weld, as shown in Figure $14 \mathrm{a}$, $\mathrm{b}$ and Table 7 .Al element in ERNi-1 wire can reduce the oxidation of molten pool, avoid $\mathrm{C}$ burning loss and eliminate the porosity in weld. With the increase of $\mathrm{Al}$ content in the wire, the $\mathrm{O}$ content in the weld decreases, and the $\mathrm{N}$ content also shows a very obvious downward trend. The porosity sensitivity of the weld is greatly reduced, which proves that Al element has a strong role in deoxidization, denitrification and reduces the porosity sensitivity of the weld ${ }^{39,40}$

The deoxidation reaction equations of $\mathrm{Al}$ element are followed: $4 \mathrm{Al}+3 \mathrm{CO}_{2}=3 \mathrm{C}+2 \mathrm{Al}_{2} \mathrm{O}_{3}, 4 \mathrm{Al}+3 \mathrm{O}_{2}=2 \mathrm{Al}_{2} \mathrm{O}_{3}, 2 \mathrm{Al}+3 \mathrm{NiO}=$ $\mathrm{Al}_{2} \mathrm{O}_{3}+3 \mathrm{Ni}$. Al can effectively reduce $\mathrm{CO}$ porosity sensitivity. With the increase of $\mathrm{Al}$ content, the number and size of pores on the longitudinal section of a certain length weld decrease. Literatures ${ }^{41,42}$ show that when the content of Al in the weld is $0.48 \%$, the number of pores in the weld decreases to the minimum. When the $\mathrm{Al}$ content is greater than $0.48 \%$, the pores with diameter greater than $1 \mathrm{~mm}$ disappear. However, there will be $\mathrm{Al}_{2} \mathrm{O}_{3}$ inclusions with a diameter greater than $10 \mu \mathrm{m}$. With the increase of $\mathrm{Al}$ content in the weld, the size of $\mathrm{Al}_{2} \mathrm{O}_{3}$ inclusions will also increase.

In addition, $\mathrm{Al}$ element has a strong effect in denitrification. The denitrification reaction equation of $\mathrm{Al}$ element is followed: $\mathrm{Al}+\mathrm{N}=\mathrm{AlN}$. Al reacts with the invading $\mathrm{N}$ element to form stable AIN particles, eliminating the nitrogen pores in pure nickel weld. Because the average temperature $(2100 \mathrm{~K}-2700 \mathrm{~K})$ of the droplet and the arc column is higher than the sublimation temperature $2450^{\circ} \mathrm{C}$ of AlN particles, most of the invaded $\mathrm{N}$ during the formation of the droplet is sublimated, which plays the role of denitrification ${ }^{43}$. When the content of $\mathrm{Al}$ in the weld is different, the size and distribution of $\mathrm{A} 1 \mathrm{~N}$ particles and blocking effect on grain growth are different. When the $\mathrm{Al}$ content is low, the fine dispersed AlN formed by the combination of Al and $\mathrm{N}$ obviously hinders the grain growth ${ }^{44}$. Thermodynamic analysis shows that $\mathrm{Al}$ has a threshold value for nitrogen fixation in the molten pool. The threshold value decreases with the increase of $\mathrm{N}$ content in the molten pool. When the Al content is lower than the threshold value, the molten pool has no nitrogen fixation effect. When the aluminum content exceeds the threshold value, the nitrogen fixation ability of the molten pool increases with the increase of $\mathrm{Al}$ content, and the nitrogen fixation product is polyhedral $\mathrm{AlN}^{45}$.

Ti element in the ERNi-1 wire is also a strong deoxidizer, and the deoxidization product is $\mathrm{TiO}_{2}$. Ti reacts with $\mathrm{O}$ mainly in the higher temperature zone of the molten pool, and rarely transits to the molten pool in the solidification stage. $\mathrm{TiO}_{2}$ with high melting point, is insoluble in molten metal, and a large number of titanium compounds form inclusions in the weld $^{46}$. As shown in Figure 14a, the size of the deoxidized product $\mathrm{TiO}_{2}$ particles reach $20 \mu \mathrm{m}$. The Ti element the ERNi-1 wire also has a strong nitrogen fixation effect, which can eliminate the nitrogen pores during the welding process ${ }^{43}$. For the nitrogen invading the droplet and pool, the harmful effect of nitrogen on the weld can be eliminated only by using nitride forming elements to form stable nitride before the molten pool solidifies. Nitrogen fixation with Ti reduces the content of $\mathrm{Al}$ element in the weld to a certain extent, which is beneficial to the microstructure transformation. Once TiN formed, it does not melted and disperses in the weld owing to the melting point of $\operatorname{TiN}\left(2950^{\circ} \mathrm{C}\right)$, as shown in Figure 13a and c. The literature ${ }^{33}$ shows that TiN can significantly refine K4169 alloy with a certain process,

Table 7. Chemical constituents of precipitated phases (at. \%)

\begin{tabular}{cccccccccc}
\hline Element & $\mathrm{C}$ & $\mathrm{N}$ & $\mathrm{O}$ & $\mathrm{Al}$ & $\mathrm{Ti}$ & $\mathrm{Ni}$ & $\mathrm{Si}$ & Precipitates \\
\hline $\mathrm{a}$ & 9.89 & 10.73 & 48.98 & 0.16 & 28.67 & 1.42 & 0.15 & $\mathrm{TiO}_{2}$ \\
\hline $\mathrm{b}$ & 4.39 & 0.0 & 58.63 & 35.74 & 0.0 & 1.17 & 0.07 & $\mathrm{Al}_{2} \mathrm{O}_{3}$ \\
\hline
\end{tabular}
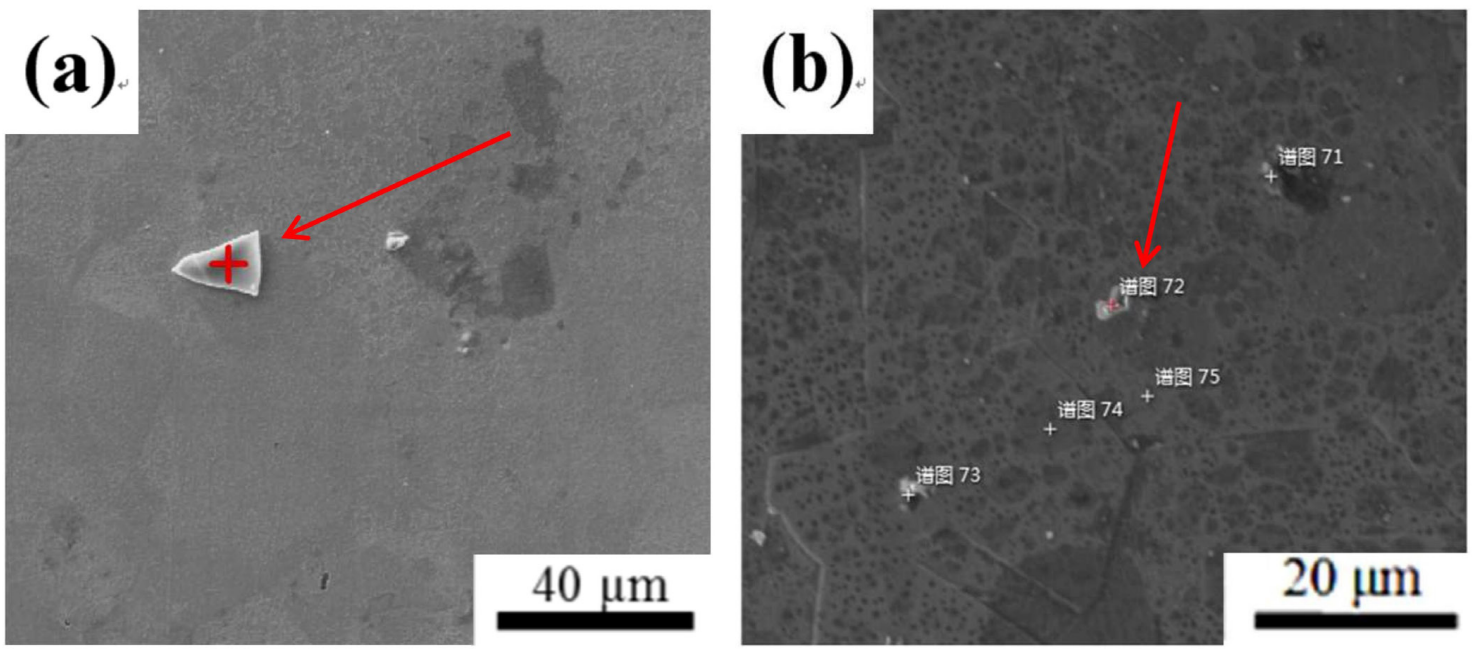

Figure 14. The precipitated phases in the wire-filled $\mathrm{PAW}$ joint (a) $\mathrm{TiO}_{2}$ (b) $\mathrm{Al}_{2} \mathrm{O}_{3}$ 
which is consistent with the prediction results obtained by mismatch degree. When the melted alloy contains TiN, the number of nucleation increases, resulting in the grain size decreases, and the equiaxed grain growth is limited with smaller dendrite growth space and increasing dendrite density. In the process of welding thermal cycle, the content of Ti in the molten pool must be strictly controlled. If the content of Ti is too small, it can't play the role of deoxidation and nitrogen fixation. However, the high content of Ti will produce a large number of inclusions, which will affect the performance of the weld. When the content of Ti is very low, the inclusions in the weld are composed of large size $\mathrm{Mn}$ and Si oxides. When proper amount of Ti is added, the inclusions transform into beneficial composite inclusions containing Ti. Excessive Ti changes the compositions of the weld inclusions with hard and brittle features, which damages the weld toughness ${ }^{47,48}$.

In conclusion, $\mathrm{Al}$ and Ti elements in ERNi-1 wire have deoxidation and nitrogen fixation effect during welding thermal cycle process, which improves the resistance of weld to carbon monoxide and nitrogen porosity, effectively reduces the tendency of porosity in weld, and improves the joint performance. When the content of $\mathrm{Al}$ and $\mathrm{Ti}$ in the molten pool is in a certain range, the products of nitrogen fixation are TiN and AIN particles, which can refine the weld grains. The content of aluminum and titanium in the molten pool is within a certain range, and the nitrogen fixation products produced during the nitrogen fixation process are TiN and AlN particles, which have the effect of refining weld grains. In addition, the alloy elements in the welding wire can supplement the alloy elements burned in the welding process. As the filler metal, the melted wire forms the joint with the melted base metal, avoiding the defects such as undercut and depression. Wire-filled PAW has a wider specification range of process parameters, and the welding process is much more stable than PAW. The Mn element in the wire reacts with $\mathrm{S}$ in the molten pool to form high melting point $\mathrm{MnS}$, which can avoid the harmful effects of S and improve the ability to resist crystal cracks. It is because of the above reasons that the microstructure and properties of wire-filled PAW joint are better than those of the PAW joint.

\section{Conclusions}

1. Both PAW and wire-filled PAW can realize the double-sided forming of $5.5 \mathrm{~mm}$ thick pure nickel sheet without grooving. The welding process of wire-filled PAW is stable, which widens the range of process parameters. The mechanical properties of wire-filled joint are better than those of PAW joint.

2. The corrosion rate of samples in $6 \% \mathrm{FeCl}_{3}$ solution is: $\mathrm{K}_{\text {PAW }}(2.8820)>\mathrm{K}_{\text {wire-filled }}(2.6908)>\mathrm{K}_{\text {base metal }}(2.3458)$. Therefore, the order of corrosion resistance of samples is: base metal, filler wire-filled PAW joint and PAW joint.

3. The alloying elements in ERNi-1 welding wire can supplement the burned alloying elements during welding process and avoiding the defects. Al and Ti elements of wire are used as deoxidizers and nitrogen additives to reduce the tendency of carbon monoxide and nitrogen pore formation in welds. The precipitated phases ( $\mathrm{TiN}, \mathrm{TiC})$ formed in the molten pool can refine the grain size of the joint and improve the crack resistance.

\section{Acknowledgments}

This work was supported by Gansu science and technology support plan project (1104GKCA051), Research support project for young teachers of Lanzhou City University(LZCUQN2018-04) and Doctoral research fund of Lanzhou City University(LZCU-BS2018-06).

\section{References}

1. Wang Y, Shi Y. Effect of magnetic field on microstructure and corrosion resistance of industrial pure nickel laser welding. Laser Technology. 2019;43(01):19-24.

2. Chen L, Xia T, Wang X, Shen J, Dong S. On surface cracks of pure nickel wire. Metallic Functional Materials. 2008;15(3):2933.

3. Jun M. Development of a reactor with pure nickel non-ferrous metal. Journal of Rocket Propulsion. 2006;32(4):47-51.

4. Chen J, Shi Y, Ni C, Jiang S, Liu J. Effect of welding parameters on formation and mechanical properties of welds during laser lap welding of industrial pure Nickel Ni201. Applied Laser. 2015;35(4):467-71.

5. Xin G, Qi J, Li X, Wang Y, Ji W, Cheng L. Molecular dynamics simulation of Ni thermal conductivity. CIESC Jorunal. 2014;65(S2):33-7.

6. Yang G. Study on the joint welding procedure of pure nickel NiSB-162-200 from abroad. Mechanical Research \& Application. 2005(3):58-60.

7. Wang X, Chai T, Xiao L, Jun X. Plasma arc welding with filler wire and microstructure of pure nickel N6. Chinese Journal of Rare Metals. 2015;39(2):103-10.

8. Wang X, Chai T, Liu X, Zhao Q, Jiang Wang SJ. Corrosion resistance and electrical conductivity of nickel alloy N6 plasma arc welded joints. Rare Metal Materials and Engineering. 2016;45(2):426-30.

9. Miao Y, Ma Z, Zhao H, Yang X, Liu J. Microstructure and performance of backing welding joint of high strength steel by bypass-current wir-heating PAW. Transactions of the China Welding Institution. 2019;40(1):99-103.

10. Hariharan SJ, Vigneshwar M, Selvamani ST, Shanmugam K, Palanikumard K. Optimizing the plasma arc welding process parameters to attain the minimum corrosion rate in the AISI 409M grade ferritic stainless steel autogenous joints. Materials Today: Proceedings. 2019, 16.

11. Cai D-T, Han S-G, Luo Z-Y. Study on the properties of microarc plasma arc welded joint of high strength 304 stainless steel sheet. Weed Technol. 2019;48(4):23-7.

12. Li H, Miao C, Yang LW, Zhang JY, He ZX, Jiao L. The development of plasma arc welding for aluminum alloy and composites. Materials Review. 2017;31(2):313-6.

13. Farias FWC, Payão JC Fo, da Silva Jr, de Moura RN, Rios MCG. Microstructural characterization of Ni-based superalloy 625 clad welded on a $9 \% \mathrm{Ni}$ steel pipe by plasma powder transferred arc. Surf Coat Tech. 2019;374:1024-37.

14. Zhou Q, Wu Z, Wang C. Microstructure and mechanical properties of TC4 titanium alloy plasma arc welded joints. Machine Building \& Automation. 2017;46(02):25-8.

15. Wu X, Chen L, Jing F, Tian Z, Gao Z. Microstructure and properties of plasma welded joints of AZ61 A magnesium alloy. Electric Welding Machine. 2017;47(10):50-2. 
16. Dong C, Wu L, Shao Y. The history and state-of-the -art of keyhole mode plasma arc welding. Zhongguo Jixie Gongcheng. 2000;11(5):577-81.

17. Zhang W. Welding metallurgy (basic principles). Beijing: Machinery Industry Press; 1999. p. 117-8

18. Xu F, Chen L, Gong SL, Li XY, Yang J. Microstructure and mechanical properties of Al-Li alloy by laser welding with filler wire. Rare Met Mater Eng. 2011;40(10):1775.

19. Pandey C, Saini N, Mahapatra MM, Kumar P. Study of the fracture surface morphology of impact and tensile tested cast and forged (C\&F) Grade 91 steel at room temperature for different heat treatment regimes. Eng Fail Anal. 2016;71:131-47.

20. Pandey C, Mahapatra MM, Kumar P, Kumar P, Saini N, Thakare JG, et al. Study on effect of double austenitization treatment on fracture morphology tensile tested nuclear grade P92 steel. Eng Fail Anal. 2018;7:158-67.

21. Veprek S. The search for novel super hard materials. J Vac Sci Technol A. 1999;17(5):2401-20.

22. Ping DH, Xie TS, Jin ZX, Li DX, Ye HQ. Preparation and properties of nanocrystalline Ti-Ni-Si alloy. Chin Shu Hsueh Pao. 1995;(17):200-5.

23. Luo Y, Xie X, Wan R, Zhu Y. Influence of thermal effect on micro-hardness of magnesium alloy weld of vacuum electron beam welding. Rare Met Mater Eng. 2017;46(2):496-502.

24. Zhang C, Liu F, Song Z, Qian L, Shen L, Zhou B. Influence of process parameters on grain size and mechanical properties of plasma and TIG hybrid weld for 4003 ferritic stainless steel. Hot Working Technology. 2017;46(7):42-6.

25. Pandey C. Mechanical and metallurgical characterization of dissimilar P92/SS304 L welded joints under varying heat treatment regimes. Metall Mater Trans, A Phys Metall Mater Sci. 2020;51(5):2126-42.

26. Jin TY, Cheng YF. In situ characterization by localized electrochemical impedance spectroscopy of the electro-chemical activity of microscopic inclusions in an X100 steel. Corros Sci. 2011;53(2):850-3.

27. Muto I, Kurokawa S, Hara N. Microelectrochemical investigation of anodic polarization behavior of $\mathrm{CrS}$ inclusion in stainless steels. J Electrochem Soc. 2009;156(11):C395-9.

28. Li W, Wu W-P, Xu J-B, Huang F, Zhu T-W. The effects of non-metallic inclusions on the weatherability of weathering steel. Chinese Rare. 2016;37(1):91-7.

29. Pan N, Song B, Zhai Q-j, Wen B. Effect of lattice disregistry on the heterogeneous nucleation catalysis of liquid steel. J Univ Sci Technol Beijing. 2010;32(2):179-82.

30. Kumar S, Pandey C, Goyal A. A microstructural and mechanical behavior study of heterogeneous P91 welded joint. Int J Press Vessels Piping. 2020;185:104-28.

31. Chen X, LI Y-X. Effects of RE/V/Ti multi-modification on grain refinement of high silicon cast steel. Transactions of Materials and Heat Treatment. 2006(3):75-80.
32. Xia TD, Chen X, Li QL, Zhao W-J. Grain refining efficiency and mechanism of pure nickel. Rare Met. 2015;34(9):6626.

33. Li X-H, Cao L-M, Zhang Y, Li A-1, Gu H-P. Effect of refiner TiN on microstructure of K4169 superalloy. Foundry. 2010;59(12):1290-2.

34. Chen M-A, Wu C-S, Wang J-G, Tang Y-M, Lou S-N. Effect of second phase particle on microstructure and toughness of CGHAZ in HSLA. Transactions of The China Welding Institution. 2002(3):37-40.

35. Yin G, Gao J, Hong Y, Dai E, Yuan X. Effect of trace amount Ti on growth tendency of austenite grain in the weld HAZ of micro alloyed Ti steel. Shanghai Metals. 1998(1):24-8.

36. Nakanishi M, Komizo Y, Seta I. Improvement of welded HAZ toughness by dispersion with nitride particles and oxide particles. J. JPn. Weld Soc. 1983;52(2):117-31.

37. Xia P, Li Z. The elimination of weld porosity of monelelectrodes. Transactions of the China Welding Institution. 1983(4):21-30.

38. Sun C-B, Shang W, Zhou J-H, Man Y-L, Wang Y-F, Cui S-S. Influence of refining and vacuum-breaking on oxygen and nitrogen contents in Ni-based superalloy. China Foundry. 2011;60(6):571-4

39. Wei Q, Hu Q, Guo F, Xiong DJ. A study of weld pore sensitivity of self-shielded, flux cored electrodes. Weld J. 2002;81(6):90-4.

40. Wei Q, Xiong D. The influence of oxygen, nitrogen and hydrogen on porosity in the weld of SSFCW. Journal of Beijing Polytechnic University, 1998(3):3-5.

41. Jiang H. Study on aluminum deoxidized Wire for $\mathrm{CO} 2$ gas shielding Arc welding. Tianjin: Tianjin University; 2012. p. 27-30

42. Abson DJ. Non-metallic inclusions in ferritic steel weld metals-a review. Weld World. 1989;27(3):31.

43. Zhi Z, Weyue Z, Banggu C. Development of a high-toughness self-shielded flux-cored wire. Transactions of The China Welding Institution. 1996;17(2):71-5.

44. Chun-Kan H. Effeet of aluminum on the magnetic properties of lamination steels. IEEE Trans Magn. 1996;32(2):471.

45. Zhang Z-W, Li W-S, Xue Z-K, Bai S-W. Control of O,N and their impact on microstructure and toughness of deposited metal of self-shielded flux cored wire. Tianjin Daxue Xuebao. 2010;43(2):186-9

46. Rong A, Pan C, Zhao L, Tian Z-L. Effect of titanium on microstructure and mechanical properties in high heat input welds. Journal of Iron and Steel Research. 2014;26(6):4753 .

47. Babu SS. The mechanism of acicular ferrite in weld deposits. Curr Opin Solid State Mater Sci. 2004;8(3-4):267-78.

48. Kim S, Kang D, Kim TW, Lee J, Lee C. Fatigue crack growth behavior of the simulated HAZ of $800 \mathrm{MPa}$ grade high-performance steel. Materials ence \& Engineering A. 2011;528(6):2331-8. 